\title{
Adult Sacro-Coccygeal Teratoma: A Brief Review
}

Ritesh Kumar $^{4^{*}}$, Deepak Kumar ${ }^{1}$, Nilesh Kumar ${ }^{2}$ and Pawan Kumar ${ }^{3}$

${ }^{1}$ Department of General Surgery, AlIMS, New Delhi, India

${ }^{2}$ Department of Anaesthesia, AIIMS, New Delhi, India

${ }^{3}$ Department of Orthopaedics, IGIMS, Patna, India

${ }^{4}$ Department of Radiotherapy, AlIMS, New Delhi, India

*Corresponding author: Ritesh Kumar, Department of Radiotherapy, AlIMS, New Delhi, India, Tel: +81-78-304-4100; Fax: + 011-65900669; E-mail: riteshkr9@gmail.com

Received date: Aug 15, 2015, Accepted date: Jan 29, 2016, Publication date: Jan 31, 2016

Copyright: () 2016 Kumar R, et al. This is an open-access article distributed under the terms of the Creative Commons Attribution License; which permits unrestricted use; distribution; and reproduction in any medium; provided the original author and source are credited.

\begin{abstract}
Sacrococcygeal teratoma (SCT) is a neoplasm that arises in the sacrococcygeal region and is derived from multiple primitive germ layers. It is the most common congenital neonatal tumor but rarely seen in adults. The standard care for sacrococcygeal teratomas is complete surgical resection of the tumor. The presence of malignant transformation is associated with a less favorable outcome.
\end{abstract}

Keywords: Adult; Sacrococcygeal; Teratoma

\section{Introduction}

Teratomas are germ cell tumors composed of multiple cell types which originate from one or more of the 3 germ cell layers. Sacrococcygeal location of these tumors is common in childhood, but rarely seen in adults. Sacrococcygeal teratoma (SCT) is the most common congenital neonatal tumor with incidence of approximately $1 / 35000$ to $1 / 40000$ live births [1]. SCT occurs more often in girls; with female to male ratio of 3-4:1. In view of rarity of incidence in adults, the evidence in literature for the management comes from case reports and few small case series. This review will highlight the issues in the management of this rare tumor in adults.

\section{Origin}

SCT develops at the base of the coccyx and is thought to be derived from the primitive streak. Different theories have been postulated regarding the origin and development of SCT [2]. Hensen Node theory suggests that SCT arise from an area under the coccyx called "Henson's Node", where primitive germ cells persist that can give rise to cells of the three major tissue layers of an embryo i.e, ectoderm, endoderm, and mesoderm. These embryonic layers eventually give rise to the various cells and structures of the body.

Other theories include accidental migration of germ cells to unusual location during embryogenesis. These cells undergo asexual reproduction, divide and multiply, eventually forming a teratoma.

\section{Clinical Presentation}

Most of the adult SCT present as intra pelvic masses whereas on the contrary in neonates, $90 \%$ of SCT are externally visible. Symptoms may be related to mass effects or bulk of the tumour, such as low back pain, bowel or urinary symptoms, venous engorgement of the lower limbs and lower extremity motor power losses [3].

\section{Pathology}

Most of the SCTs are cystic and benign and only 1-2\% are malignant [4]. The cysts may be filled with serous fluid, mucoid, or sebaceous material and lined by true epithelium. Macroscopic examination commonly shows partially cystic lesions. Microscopic features include presence of derivatives of more than one germ layer. Based on histopathological fatures, SCT are classified into three categories: entirely mature adult-type tissue, immature and malignant.

Mature teratoma (also referred to as benign teratoma) contains obvious epithelial-lined structures as well as mature cartilage and striated or smooth muscle. Immature teratomas contain primitive mesoderm, endoderm or ectoderm mixed with more mature elements. Malignant teratomas have frankly malignant tissue of germ cell origin in addition to mature and/or embryonic tissues.

\section{Investigative work-up}

Investigative work-up includes routine hemogram, biochemistry and Chest X ray. CT and MRI are the most significant tools to characterize the mass, to evaluate the intrapelvic extension and relationship to other structures.

MRI is superior to CT in terms of specificity and accuracy for visualizing the soft-tissue extent in SCT, containing abundant fat and fluid (Figure 1). Serum tumor markers (AFP, HCG, LDH) needs to ascertained. Elevated tumor markers are suggestive of malignant transformation as they are rarely elevated in beningn tumours $[5,6]$.

Other imaging examinations, including transvaginal and transrectal ultrasonography and Barium enema gives additional information regarding local extension. 


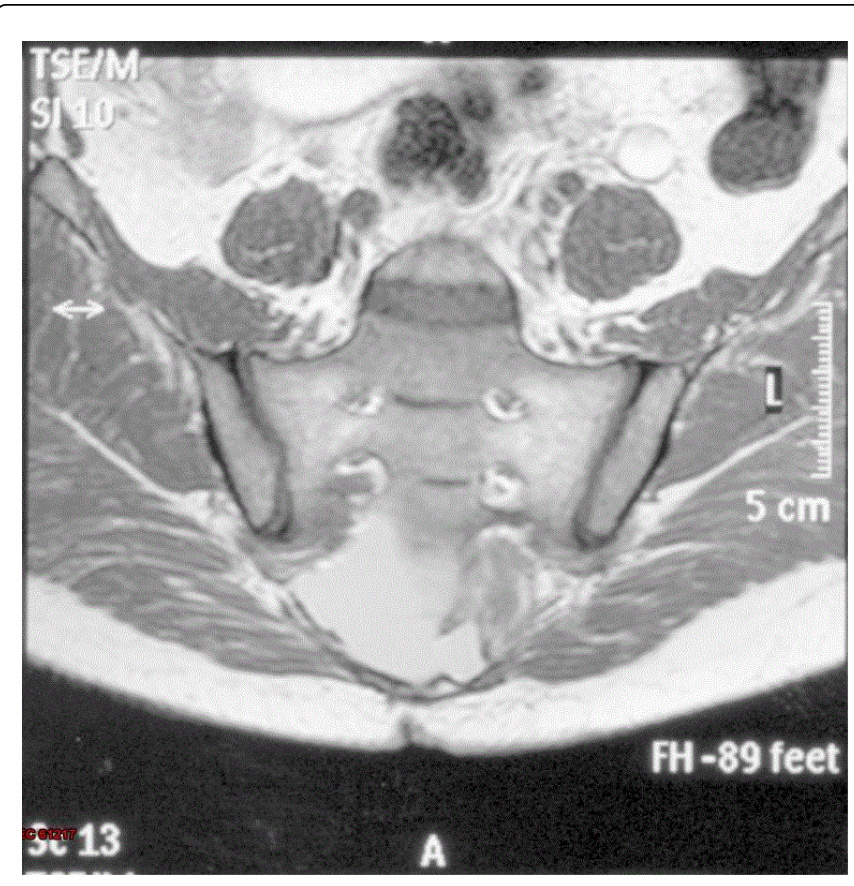

Figure 1: MRI showing a large mass lesion in pre-sacral area with large soft tissue component.

\section{Differential diagnosis}

The differential diagnosis of SCT in adults includes chordoma, meningocele, giant cell tumor of sacrum, osteomyelitis of sacrum, pilonidal cysts, rectal duplication cysts, fistula with presacral extension and abscess formation, post injection granuloma, and tuberculosis [7].

\section{Classification}

SCT is classified in four types in Altman classification system. This is an anatomico-surgical classification described in 1974 by Altman et al. [8].

Type I: predominantly external with a minimal presacral component, projecting from the sacrococcygeal region and distorting the buttocks

Type II: predominantly external with a significant intrapelvic component

Type III: predominantly intrapelvic with a small external buttock mass

Type IV: entirely internal without any external or buttock component (also known as presacral teratoma).

Type III is the most common type in adults

\section{Treatment}

Complete surgical excision is the mainstay definitive treatment of SCT $[5,9]$. As these tumors are contiguous with the coccyx, which may contain the nidus of totipotential cells. Concomitant excision of the coccyx is usually performed to eliminate the risk of tumor recurrence, which is reportedly $30-40 \%$ without coccygectomy. Massive bleeding is the major surgical morbidity for the surgical excision of SCT [10]. Transcatheter arterial embolization may be useful for reducing blood loss during the excision of a large-sized tumor [11].

If the tumor is histologically benign (mature tissues only) or immature teratoma without frankly malignant tissue, complete excision is adequate. For malignant teratomas, surgical excision alone is inadequate, and patients should receive additional treatment with chemotherapy and/or radiotherapy. In view of the rarity of these tumors, there has been no standard recommendation for the use of chemotherapy or radiation. However, malignant teratoma has poor prognosis due to its tendency to local infiltration, recurrence and metastasis. It is recommended that malignant SCT should be treated by a multidisciplinary surgical team at an advanced oncological center.

\section{Complications}

Common surgical morbidities include bladder dysfunction, fecal incontinence and dysesthesia, as the nervous plexuses innervating the bladder and rectum, such as the pelvic splanchnic nerves, are frequently injured during surgical excision and local pressure from tumor [10].

\section{Conclusions}

SCT is an uncommon tumor in adults, which presents as a gradually enlarging sacrococcygeal cystic mass. The diagnosis of adult SCT mainly depends on a combination of medical imaging examinations, however, with use of tumor biomarker tests may aid in the differentiation and exclude the possibility of malignant SCT. Early complete excision is the mainstay of treatment for SCT. Laparoscopic approach for surgical excision has also been used in management of these tumours $[12,13]$. The presence of malignant transformation and incomplete excision are associated with a less favorable prognosis and outcome.

\section{References}

1. Schropp KP, Lobe TE, Rao B, Mutabagani K, Kay GA, et al. (1992) Sacrococcygeal teratomas: the experience of four decades. J Pediatr Surg 27: $1075-1079$

2. Ghosh J, Eglinton T, Frizelle FA, Watson AJ (2007) Presacral tumours in adults. Surgeon 5: 31-38.

3. Al-Essa AA, Malik TA, Baghdadi MK, El Tayeb AA (2004) Adult sacrococcygeal teratomas. Saudi Med J 25: 367-369.

4. Gurda GT, VandenBussche CJ, Yonescu R, Gonzalez-Roibon N, Ellis CL, et al. (2014) Sacrococcygeal teratomas: clinico-pathological characteristics and isochromosome 12p status. Modern Pathology 27: 562-568.

5. Audet IM, Goldhahn RT, Dent TL (2000) Adult sacrococcygeal teratomas. Am Surg 66: 61-65.

6. Billmire DF, Grosfeld JL (1986) Teratomas in childhood: analysis of 142 cases. J Pediatr Surg 21: 548-551.

7. Turner ML, Mulhern CB, Dalinka MK (1981) Lesions of the sacrum: differential diagnosis and radiological evaluation. Jama 245: 275-277.

8. Altman RP, Randolph JG, Lilly JR (1974) Sacrococcygeal teratoma: American Academy of Pediatrics surgical section survey-1973. J Pediatr Surg 9: 389-398.

9. Wishnia SC, Rosen JE, Hamid MA, Haas S, Moreno-Ruiz N (2008) Management of a presacral teratoma in an adult. Journal of Clinical Oncology 26: 2586-2589.

10. Simpson PJ, Wise KB, Merchea A, Cheville JC, Moir C, et al. (2014) Surgical outcomes in adults with benign and malignant sacrococcygeal 
Citation: Kumar R, Kumar D, Kumar N, Kumar P (2016) Adult Sacro-Coccygeal Teratoma: A Brief Review. J Nucl Med Radiat Ther 7: 278. doi: 10.4172/2155-9619.1000278

Page 3 of 3

teratoma: a single-institution experience of 26 cases. Dis Colon Rectum 57: 851-857.

11. Yang HL, Chen KW, Wang GL, Lu J, Ji YM, et al. (2010) Pre-operative transarterial embolization for treatment of primary sacral tumors. J Clin Neurosci 17: 1280-1285.
12. Tsutsui A, Nakamura T, Mitomi H, Onozato W, Sato T, et al. (2011) Successful laparoscopic resection of a sacrococcygeal teratoma in an adult: report of a case. Surgery 41: 572-575.

13. Sukhadiya MV, Das U (2015) Laparoscopic Approach to Type IV Sacrococcygeal Teratoma in an Adult. Indian J Surg 77: 62-63. 